\title{
Female-to-Male Transsexual Phenotype
}

National Cancer Institute

\section{Source}

National Cancer Institute. Female-to-Male Transsexual Phenotype. NCI Thesaurus. Code C47838.

An individual who was female at birth based on physical characteristics and has undergone hormonal therapy and/or surgical procedures in order to develop more male physical characteristics. 